\title{
The Comparative Reactivity Method - a new tool to measure total OH Reactivity in ambient air
}

\author{
V. Sinha, J. Williams, J. N. Crowley, and J. Lelieveld \\ Max Planck Institute for Chemistry, J.J. Becher Weg 27, 55128 Mainz, Germany \\ Received: 13 November 2007 - Published in Atmos. Chem. Phys. Discuss.: 19 December 2007 \\ Revised: 12 March 2008 - Accepted: 4 April 2008 - Published: 22 April 2008
}

\begin{abstract}
Hydroxyl $(\mathrm{OH})$ radicals play a vital role in maintaining the oxidizing capacity of the atmosphere. To understand variations in $\mathrm{OH}$ radicals both source and sink terms must be understood. Currently the overall sink term, or the total atmospheric reactivity to $\mathrm{OH}$, is poorly constrained. Here, we present a new on-line method to directly measure the total $\mathrm{OH}$ reactivity (i.e. total loss rate of $\mathrm{OH}$ radicals) in a sampled air mass. In this method, a reactive molecule $(X)$, not normally present in air, is passed through a glass reactor and its concentration is monitored with a suitable detector. $\mathrm{OH}$ radicals are then introduced in the glass reactor at a constant rate to react with $X$, first in the presence of zero air and then in the presence of ambient air containing VOCs and other $\mathrm{OH}$ reactive species. Comparing the amount of $X$ exiting the reactor with and without the ambient air allows the air reactivity to be determined. In our existing set up, $X$ is pyrrole and the detector used is a proton transfer reaction mass spectrometer. The present dynamic range for ambient air reactivity is about 6 to $300 \mathrm{~s}^{-1}$, with an overall maximum uncertainty of $25 \%$ above $8 \mathrm{~s}^{-1}$ and up to $50 \%$ between $6-$ $8 \mathrm{~s}^{-1}$. The system has been tested and calibrated with different single and mixed hydrocarbon standards showing excellent linearity and accountability with the reactivity of the standards. Potential interferences such as high NO in ambient air, varying relative humidity and photolysis of pyrrole within the setup have also been investigated. While interferences due changing humidity and photolysis of pyrrole are easily overcome by ensuring that humidity in the set up does not change drastically and the photolytic loss of pyrrole is measured and taken into account, respectively, $\mathrm{NO}>10 \mathrm{ppb}$ in ambient air remains a significant interference for the current configuration of the instrument. Field tests in the tropical rainforest of Suriname $\left(\sim 53 \mathrm{~s}^{-1}\right)$ and the urban atmosphere
\end{abstract}

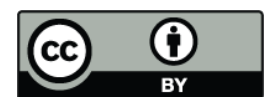

Correspondence to: J. Williams (williams@mpch-mainz.mpg.de) of Mainz $\left(\sim 10 \mathrm{~s}^{-1}\right)$ Germany, show the promise of the new method and indicate that a significant fraction of $\mathrm{OH}$ reactive species in the tropical forests is likely missed by current measurements. Suggestions for improvements to the technique and future applications are discussed.

\section{Introduction}

Every year, approximately 1.3 billion tonnes of carbon are released into the troposphere due to natural and anthropogenic gaseous emissions (Goldstein et al., 2004). Photochemical reactions, initiated by the hydroxyl radical $(\mathrm{OH})$, oxidize many of these emitted primary atmospheric pollutants such as carbon monoxide $(\mathrm{CO})$, sulphur dioxide $\left(\mathrm{SO}_{2}\right)$, nitrogen oxides $\left(\mathrm{NO}_{\mathrm{x}}=\mathrm{NO}\right.$ and $\left.\mathrm{NO}_{2}\right)$ and VOCs (Volatile Organic Compounds) into forms, which are more readily removed from the atmosphere by deposition or formation of aerosol. Ultimately, if a carbon compound remains in the gas phase it will be oxidised in radical reaction chains to $\mathrm{CO}_{2}$ and water, which is vital for maintaining the self cleansing capacity of the atmosphere (Heard and Pilling, 2003; Lelieveld et al., 2004). In order to ascertain how well we understand these $\mathrm{OH}$ initiated photochemical processes, measured ambient $\mathrm{OH}$ radical concentrations from field studies are often compared with $\mathrm{OH}$ radical concentrations predicted by photochemical models (e.g. Poppe et al., 1994; Hofzumahaus et al., 1996; Carslaw et al., 2002; Holland et al., 2003; Martinez et al., 2003; Olson et al., 2004; Ren et al., 2005; Ren et al., 2006; Smith et al., 2006).

The accuracy of photochemical models depends to a large extent on how well the $\mathrm{OH}$ sources, $\mathrm{OH}$ sinks and associated chemical mechanisms are represented. For example, if the model predicts significantly higher $\mathrm{OH}$ concentrations than the measured $\mathrm{OH}$ concentrations, it could be due to an overestimation of the $\mathrm{OH}$ sources and/or an underestimation of the OH sinks. Currently, the source term is better understood

Published by Copernicus Publications on behalf of the European Geosciences Union. 
and more readily quantified than the sink. While the source involves a limited number of reactants and rate coefficients that can be determined using available instruments, the sink is dependent on a multitude of species, all of which compete for the available $\mathrm{OH}$. An accurate sink term can constrain models and thus clarify the possible reasons for discrepancies between models and measurements. Atmospheric $\mathrm{OH}$ is produced primarily by the photolysis of $\mathrm{O}_{3}$ with solar $\mathrm{UV}(\lambda \leq 320 \mathrm{~nm})$ radiation followed by reaction of the excited oxygen atoms $\left(\mathrm{O}^{1} \mathrm{D}\right)$ with water vapour,

$\mathrm{O}_{3}+h v \rightarrow \mathrm{O}_{2}+\mathrm{O}\left({ }^{1} \mathrm{D}\right)$

$\mathrm{O}\left({ }^{1} \mathrm{D}\right)+\mathrm{H}_{2} \mathrm{O} \rightarrow 2 \mathrm{OH}$

The reactions of $\mathrm{OH}$ radicals with VOCs in the atmosphere can be summarized by the following four generalized reactions. In the first step, $\mathrm{OH}$ attacks a hydrocarbon in the presence of $\mathrm{O}_{2}$,

$\mathrm{RH}+\mathrm{OH}+\mathrm{O}_{2} \rightarrow \mathrm{RO}_{2}+\mathrm{H}_{2} \mathrm{O}$

to produce water and an alkyl peroxy radical, where $R=$ any organic moiety.

Next, the alkyl peroxy radical may react with NO when present,

$\mathrm{RO}_{2}+\mathrm{NO} \rightarrow \mathrm{RO}+\mathrm{NO}_{2}$

to produce an alkoxy radical that reacts with $\mathrm{O}_{2}$,

$\mathrm{RO}+\mathrm{O}_{2} \rightarrow$ carbonyls $+\mathrm{HO}_{2}$

This step produces a carbonyl and $\mathrm{HO}_{2}$. Alternatively, the alkyl peroxy radicals, $\mathrm{RO}_{2}$ and $\mathrm{HO}_{2}$, may also react with each other,

$\mathrm{RO}_{2}+\mathrm{R}^{\prime} \mathrm{O}_{2} \rightarrow$ peroxides, alcohols, carbonyls $+\mathrm{O}_{2}$

resulting in the production of peroxides, alcohols and carbonyls, which may dissolve into the liquid phase and precipitate out of the atmosphere or further react with $\mathrm{OH}$. Both $R$ and $R^{\prime}$ can be any organic moiety.

Reaction (3) represents a major sink term of $\mathrm{OH}$ radicals in the atmosphere, namely reaction with the generic hydrocarbon RH. Often, the overall sink term is estimated by calculating $\mathrm{OH}$ loss frequencies (product of concentration and rate coefficient) for all individually measured species and summing them. Thus, the $\mathrm{OH}$ reaction frequency (also termed $\mathrm{OH}$ reactivity) of a chemical is given by

$\mathrm{OH}$ reaction frequency of reactant

$X\left(\mathrm{~s}^{-1}\right)=k_{(X+\mathrm{OH})}[X]$

where $k_{(X+\mathrm{OH})}$ is the rate coefficient for the reaction of $X$ with $\mathrm{OH}$

However, it is not certain whether all relevant $\mathrm{OH}$ reactive species are measured by the suite of measurement techniques deployed in current field studies. Roberts et al. (1998) and Maris et al. (2003) determined the total carbon budget of ambient VOCs, but while this information is useful for understanding what fraction of the carbon budget remains unidentified by VOC measurements, it lacks the critical information about how reactive the missing carbon might be for chemical reactions in the atmosphere (e.g. $10 \mathrm{ppbC}$ of isoprene is not equivalent to $10 \mathrm{ppbC}$ of methane for $\mathrm{OH}$ reactivity). Lewis et al. (2000) identified more than 500 reactive VOCs in urban air using comprehensive gas chromatography and concluded that a large number of VOCs, particularly those with more than 6 carbon atoms and especially aromatics, are not resolved in the more commonly employed single column gas chromatography measurements. More recently, Goldstein et al. (2004) and Holzinger et al. (2005) reported the presence of unknown reactive biogenic compounds (up to 30 times the emission of total monoterpenes observed in the forest canopy on a molar basis), from a pine forest in California. Direct $\mathrm{OH}$ reactivity measurement techniques circumvent the daunting task of measuring all the $\mathrm{OH}$ reactive species individually, in order to obtain the total $\mathrm{OH}$ reactivity (sink) and can even serve as a diagnostic tool for missing reactivity due to possibly unmeasured reactive species (Di Carlo et al., 2004). Additionally, $\mathrm{OH}$ production rates can also be estimated by simultaneous measurements of total $\mathrm{OH}$ reactivity and $\mathrm{OH}$ concentrations, assuming the steady state of $\mathrm{OH}$ using

$\frac{d[\mathrm{OH}]}{d t}=P_{\mathrm{OH}}-k[\mathrm{OH}]=0$

where $P_{\mathrm{OH}}$ and $k$ represent the $\mathrm{OH}$ production rate and its measured first-order decay constant, respectively. Finally, information about the lifetime of $\mathrm{OH}$ is also easily obtained by taking the reciprocal of the measured $\mathrm{OH}$ reactivity.

In the last decade, new instruments capable of directly measuring the $\mathrm{OH}$ reactivity of ambient air have been developed (Kovacs and Brune, 2001; Sadanaga et al., 2004b). With some variations, all of them employ laser induced fluorescence (LIF) to monitor the loss rate (decay) of $\mathrm{OH}$ radicals in a reactor in the presence of ambient air. While these measurement systems have provided new insights on the $\mathrm{OH}$ reactivity budget, their cost, complexity and large size are deterrents to their widespread deployment for field studies. Thus, other techniques capable of measuring the total $\mathrm{OH}$ reactivity of ambient air that are more economical and portable than the existing LIF based method, would be a valuable addition to current atmospheric measurements.

In this study, we present a new method for direct online measurements of the total $\mathrm{OH}$ reactivity of ambient air. This method can be easily integrated with commonly employed in-situ analytical techniques such as gas chromatography and chemical ionization mass spectrometry at modest additional costs. Presented below is a detailed description of the general concept, the reactor design, the method validation and calibration, choice of reagent (in this case pyrrole; $\mathrm{C}_{4} \mathrm{H}_{5} \mathrm{~N}$ ) and the detector system employed (in this case a proton transfer reaction mass spectrometer). First field results from the 
tropical rainforest in Suriname and the urban atmosphere of Mainz, Germany, are shown and potential interferences from $\mathrm{NO}$ and relative humidity are investigated. Finally an outlook for future applications of the new method is given.

\section{Methodology}

\subsection{Concept of Comparative Reactivity Method (CRM)}

Figure 1 illustrates the general concept schematically. A reactive molecule $(X)$, not normally present in air, is introduced into a glass reactor and its concentration $\mathrm{C} 1$ is monitored with a suitable detector, in the air exiting the reactor. After some time when $\mathrm{C} 1$ is well determined, synthetically generated $\mathrm{OH}$ radicals $(\mathrm{OH}<[X])$ are introduced into the reactor at a constant rate to react with $\mathrm{X}$. This causes $\mathrm{C} 1$, the monitored concentration of $X$, to decrease to $\mathrm{C} 2$, as $\mathrm{X}$ reacts with the $\mathrm{OH}$ radicals. The decrease in the monitored concentration of $X$ (from $\mathrm{C} 1$ to $\mathrm{C} 2$ ) also gives the initial concentration of the $\mathrm{OH}$ radicals, as all the $\mathrm{OH}$ is completely titrated by $X$. Next, an air sample containing reactive species is introduced into the glass reactor. The various species present in ambient air then compete with $X$ for the available $\mathrm{OH}$ radicals, so that the concentration of $X$ in the air exiting the reactor increases to $\mathrm{C} 3$. Comparing the amount of $X$ exiting the reactor without $(\mathrm{C} 2)$ and with the ambient air (C3) allows the introduced air sample's $\mathrm{OH}$ reactivity to be determined in a quantitative manner, provided the system is suitably calibrated. Some general criteria that the reagent molecule $X$ must satisfy are:

1. it reacts with $\mathrm{OH}$ at a suitable rate so as to compete with reactive species in ambient air;

2. the rate coefficient for reaction with $\mathrm{OH}$ should be well established;

3. it must be volatile (to make into a good bottled standard);

4. it must have the necessary physical and chemical properties for easy and accurate detection (without interferences) using a suitable detector (e.g. the proton affinity of $X$ should be greater than water to be detectable by a PTR-MS);

5. it should not be present in ambient air (under normal circumstances) as this can complicate the analysis. In the present version of the CRM developed in Mainz, the reagent molecule $\mathrm{X}$ is pyrrole $\left(\mathrm{C}_{4} \mathrm{H}_{5} \mathrm{~N}\right)$ and the detector is a PTR-MS.

2.2 Determining $\mathrm{OH}$ reactivity: derivation of the basic equation for CRM

Based on competitive kinetics, an expression may be derived for the total $\mathrm{OH}$ reactivity of the analysed air sample (de-

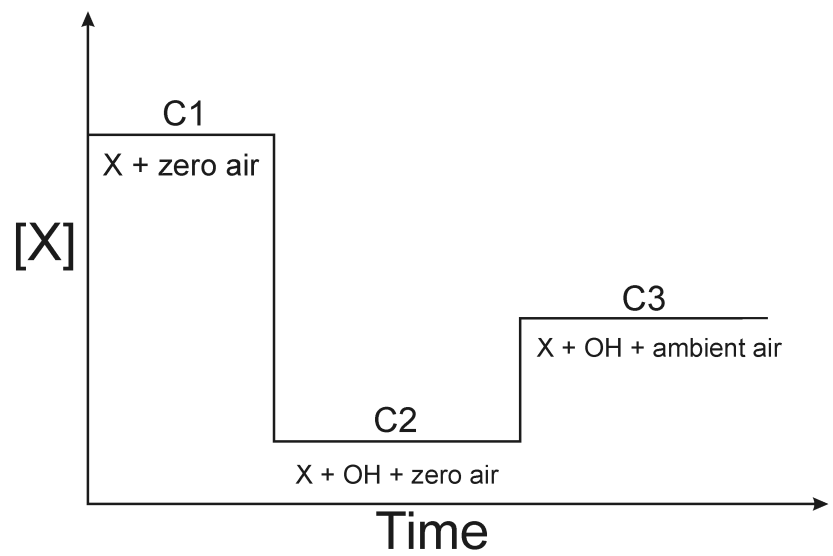

Fig. 1. Schematic illustrating concept of the Comparative Reactivity Method.

noted by $\left.R_{\text {air }}\right)$ in terms of the measured pyrrole signals $\mathrm{C} 1$, $\mathrm{C} 2$ and $\mathrm{C} 3$ (shown in Fig. 1).

Consider the loss of $\mathrm{OH}$ in a two component reactive mixture consisting of pyrrole and air, the equations describing the loss of $\mathrm{OH}$ are:

$\mathrm{OH}+$ pyrrole $\rightarrow$ products

$\mathrm{OH}+$ air $\rightarrow$ products

leading to the rate expression

$-\delta[\mathrm{OH}] / d t=k_{p}[\mathrm{OH}][$ Pyrrole $]+k_{\mathrm{OH}+\operatorname{air}}[\mathrm{OH}][$ air $]$

where $k_{p}$ is the rate coefficient for reaction of $\mathrm{OH}$ with pyrrole and $k_{\mathrm{OH}+\text { air }}$ is the effective rate coefficient of all reactive components in the air sample and [air] is their summed concentration. As [pyrrole] is $>[\mathrm{OH}]$ the first order loss rate coefficients of $\mathrm{OH}$ in its reactions with pyrrole and air are given approximately by $R_{p}=k_{p}$ [Pyrrole] and $R_{\text {air }}=k_{\text {air }}$ [air], respectively, resulting in a total loss rate coefficient of $R_{p}+R_{\text {air. }}$. If all $\mathrm{OH}$ is lost in reaction with pyrrole and air, the change in pyrrole concentration $(\mathrm{C} 1-\mathrm{C} 3)$ is approximately given by

$(\mathrm{C} 1-\mathrm{C} 3)=\frac{R_{p}}{R_{p}+R_{\text {air }}} \cdot[\mathrm{OH}]$

As discussed previously, the $\mathrm{OH}$ concentration is given by the loss of pyrrole in the absence of air (C1-C2), so that:

$(\mathrm{C} 1-\mathrm{C} 3)=\frac{R_{p}}{R_{p}+R_{\text {air }}} \cdot(\mathrm{C} 1-\mathrm{C} 2)$

rearranging we get

$R_{\text {air }}=\left\{\frac{(\mathrm{C} 1-\mathrm{C} 2)}{(\mathrm{C} 1-\mathrm{C} 3)}-1\right\} \cdot R_{p}$

and, equating [pyrrole] to $\mathrm{C} 1$,

$R_{\text {air }}=\left\{\frac{(\mathrm{C} 1-\mathrm{C} 2)}{(\mathrm{C} 1-\mathrm{C} 3)}-1\right\} \cdot k_{p} \mathrm{C} 1$ 


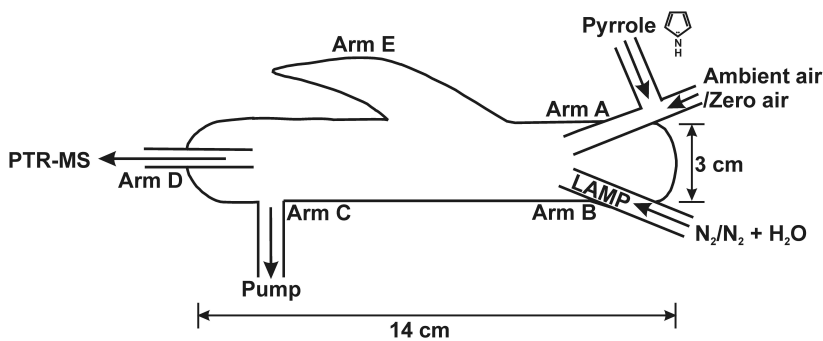

Fig. 2. Schematic of the glass reactor used in the Mainz CRM instrument.

which is numerically equivalent to

$R_{\text {air }}=\frac{(\mathrm{C} 3-\mathrm{C} 2)}{(\mathrm{C} 1-\mathrm{C} 3)} \cdot k_{p} \mathrm{C} 1$

$[\mathrm{OH}], \mathrm{C} 1, \mathrm{C} 2$ and $\mathrm{C} 3$ have the units of molecules $\mathrm{cm}^{-3}$ and $k_{p}$ has the unit of $\mathrm{cm}^{3}$ molecule $\mathrm{e}^{-1} \mathrm{~s}^{-1}$, so that the unit for $R_{\text {air }}$ is $\mathrm{s}^{-1}$. It should be noted that Eq. (8) assumes that mixing within the reactor does not favour reaction of $X$ with $\mathrm{OH}$ compared with the reaction of ambient air with $\mathrm{OH}$ or vice versa. It also assumes that throughout its reactive lifetime the $\mathrm{OH}$ is partitioned to the pyrrole and air reactants according to their initially available concentrations, i.e. the reaction takes place under pseudo-first order conditions. We examine the effect of this assumption in Sect. 4.1 when we present the results of some numerical simulations of the reactor.

\section{Experimental}

The simple set up consists of a small glass reactor (where pyrrole and ambient air/standards mix and react with $\mathrm{OH}$ radicals), a PTR-MS which detects pyrrole in the air exiting the reactor and a set of mass flow controllers along with two gas bottles (nitrogen and zero air).

\subsection{Glass reactor}

Figure 2 shows a diagram of the glass reactor used along with its inlets and outlets labelled as arms A, B, C, D and E. The length and volume of the glass reactor are approximately $14 \mathrm{~cm}$ and $94 \mathrm{~cm}^{3}$, respectively. The typical flow rate inside

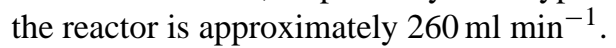

Gas phase pyrrole (Westfalen A.G., stated uncertainty 5\%; $10 \mu \mathrm{mol} \mathrm{mol}^{-1}$ ) is mixed with zero air (Synthetic air, Westfalen A.G., $99.999 \%$ purity, $<0.5 \mu \mathrm{mol} \mathrm{mol}^{-1}$ THC) and introduced through inlet $\mathrm{A}$ at a constant flow. Its concentration is monitored in the air exiting the reactor (outlet $\mathrm{D}$ ) with a PTR-MS. Inlet B consists of a pen ray spectral mercury vapour lamp (L.O.T Oriel GmbH and Co. KG), over which humidified nitrogen/nitrogen (Westfalen A.G., 99.9999\% purity) is passed at a constant flow rate. The humidification is accomplished by bubbling gaseous nitrogen through water, which is maintained at room temperature $(298 \mathrm{~K})$. When the lamp is switched on, $\mathrm{OH}$ and $\mathrm{H}$ radicals are produced due to photolysis of the water vapour (at $\lambda=184.9 \mathrm{~nm}$ ) present in the humidified nitrogen. The lamp is $5 \mathrm{~cm}$ long and the maximum time the $\mathrm{OH}$ radicals spend in arm $\mathrm{B}$ before they emerge into the glass reactor, is $0.6 \mathrm{~s}$. This method of producing $\mathrm{OH}$ radicals has been used extensively in gas phase kinetic studies, including calibration of $\mathrm{OH}$ measurement instruments, and for more details the reader is referred to Heard and Pilling (2003) and references therein.

The tapered arm E is a Wood's horn which minimizes reflection of the mercury lamp down the reactor and hence photochemical reactions along the length of the glass reactor. Outlet $\mathrm{C}$ is connected to an exhaust pump (Model NO22AV.18, KNF Neuberger, Germany) that draws out the excess air from the main flow. The total incoming flow rate $(\mathrm{A}+\mathrm{B})$ is circa $260 \mathrm{ml} \mathrm{min}^{-1}$, slightly more $\left(\sim 5 \mathrm{ml} \mathrm{min}^{-1}\right)$ than the combined flow through the exhaust pump (arm C) and the PTR-MS. To prevent an over-pressure from building up within the reactor, and to ensure that the pressure in the reactor is always atmospheric pressure (760 Torr), one of the lines linked to arm A (with a T-shaped Teflon joint) is kept open-ended at all times. The pressure and temperature inside the reactor are also monitored using a digital pressure manometer (Model 13 AN, Greisinger Elektronik, Germany) and a temperature probe connected to the line exiting arm C. A total of four mass flow controllers (MKS Instruments, Deutschland $\mathrm{GmbH}$ ) are used to maintain constant flows in arm A (one each for pyrrole and zero air), arm B (one for nitrogen) and arm C (for the exhaust pump). All the gas carrier lines leading into and from the reactor are plumbed using short $(<1 \mathrm{~m}) 1 / 4$ inch $(0.635 \mathrm{~cm})$ (outer diameter; o.d.) and $1 / 8$ inch $(0.3175 \mathrm{~cm})$ (o.d.) Teflon tubing.

To sample ambient air for reactivity, the zero air is switched off and an equivalent amount (130-150 $\left.\mathrm{ml} \mathrm{min}^{-1}\right)$ of ambient air is pumped in, using a Teflon VOC sampling pump (Laboport N86-KN18; at arm A). This causes dilution of the ambient air within the reactor, and the dilution factor has to be taken into account when determining the total $\mathrm{OH}$ reactivity of the introduced ambient air. It is worth mentioning that the ambient air is not subject to any gas chromatography column, preconcentration step or laser excitation and its reactivity is directly converted into a modulation of the pyrrole signal so that any potential losses of VOCs and/or associated artefacts are minimised. Typical pyrrole and $\mathrm{OH}$ radical mixing ratios (the signal $\mathrm{C} 1-\mathrm{C} 2$ in Fig. 1) in the set up are $\sim 120 \mathrm{nmol} \mathrm{mol}^{-1}\left(\sim 3.23 \times 10^{12}\right.$ molecules $\left.\mathrm{cm}^{-3}\right)$ and up to $100 \mathrm{nmol} \mathrm{mol}^{-1}\left(\sim 2.69 \times 10^{12}\right.$ molecules $\left.\mathrm{cm}^{3}\right)$, respectively.

\subsection{PTR-MS: the detector}

The mixing ratio of pyrrole in the air exiting the glass reactor through arm D was monitored using a proton transfer reaction mass spectrometer (PTR-MS), a device used extensively over the last decade to measure ambient VOCs (Lindinger et 
al. 1998a; de Gouw and Warneke, 2007). Within the instrument, organic species with a proton affinity greater than water are chemically ionised by proton transfer with $\mathrm{H}_{3} \mathrm{O}^{+}$ions and the products are detected using a quadrupole mass spectrometer (Lindinger et al., 1998b). The entire inlet system of the PTR-MS including switching valves is made of Teflon. Details about the operation of the PTR-MS used here, including its mass identifications, its sensitivity and detection limits for masses other than pyrrole $\left(\mathrm{C}_{4} \mathrm{H}_{5} \mathrm{~N}\right)$ are given elsewhere (Williams et al. 2001, Salisbury et al., 2003; Sinha et al., 2007a). Pyrrole is detectable by the PTR-MS since its proton affinity $\left(209.2 \mathrm{kcal} \mathrm{mol}^{-1}\right)$ is higher than that of water $\left(165.2 \mathrm{kcal} \mathrm{mol}^{-1}\right)$ and the signal is observed without fragmentation at mass $68\left(\mathrm{C}_{4} \mathrm{H}_{5} \mathrm{NH}^{+}\right)$. There are no known species in ambient air that could interfere at mass 68 within the PTR-MS, and experience from field campaigns has shown this mass to be stable. It is advantageous that mass 68 is an even mass (pyrrole has a nitrogen atom), since most organic compounds detectable by PTR-MS (e.g. methanol, acetone, acetaldehyde and isoprene) are detected after protonation at odd masses. Pyrrole is not normally present in ambient air, and has only been observed in emission plumes from specific energy production processes such as coal gasification and shale and coal-based oil production (Sickles et al., 1977).

Calibrations performed with custom prepared pyrrole standards from Westfalen A.G. show that the protonated ion of pyrrole $(m / z=68)$ does not fragment within the instrument and high mixing ratios of up to circa $250 \mathrm{nmol} \mathrm{mol}^{-1}$ do not significantly decrease the signal of the $\mathrm{H}_{3} \mathrm{O}^{+}$reagent ions. Furthermore, no significant humidity effect has been observed at the pyrrole signal (mass 68). The linearity of the pyrrole signal is excellent $(r=0.99$ between the investigated range of 0.5 to $250 \mathrm{nmol} \mathrm{mol}^{-1}$ ) and the total uncertainty in the measured pyrrole signal is estimated to be $11 \%$. This includes a $5 \%$ accuracy error inherent in the pyrrole gas standard and a $2 \sigma$ precision error of $6 \%$, while measuring pyrrole at $25 \mathrm{nmol} \mathrm{mol}^{-1}$ (the typical baseline value, C2, Fig. 1). As a detector for the CRM technique, the PTR-MS offers the added advantage of tracking humidity changes in the air exiting the glass reactor (more details in Sect. 4.2.3), by monitoring masses 37 (cluster ion $\mathrm{H}_{3} \mathrm{O}^{+} \cdot \mathrm{H}_{2} \mathrm{O}$ ) and 55 (cluster ion $\left.\mathrm{H}_{3} \mathrm{O}^{+} \cdot\left(\mathrm{H}_{2} \mathrm{O}\right)_{2}\right)$, which can be used as proxies for water vapour in the air sampled by the PTR-MS. Further details of this approach are available in Ammann et al. (2006).

\section{Results}

\subsection{Calibrations and method validation}

Several tests with single and mixed hydrocarbon standards were performed to ascertain whether the Comparative Reactivity Method can reliably quantify samples of known $\mathrm{OH}$ reactivity. Figure 3 shows an example plot of the measured raw reactivity data versus time. A propane gas standard (Westfalen A.G.; $33 \mu \mathrm{mol} \mathrm{mol}^{-1}$; stated uncertainty $4 \%$ ) was introduced at different concentrations through the same line that is used to introduce ambient air into the glass reactor. The PTR-MS is blind to propane since the proton affinity of propane is less than that of water. The occasions when propane was introduced are indicated by shaded areas. As can be seen in Fig. 3, the baseline value (corresponding to $\mathrm{C} 2$ in Fig. 1) of pyrrole is $\sim 25 \mathrm{nmol} \mathrm{mol}^{-1}$ and after every modulation (increase in signal corresponding to $\mathrm{C} 3$ in Fig. 1) with propane concentrations of $1203 \mathrm{nmol} \mathrm{mol}^{-1}, 769 \mathrm{nmol}$ $\mathrm{mol}^{-1}$ and $465 \mathrm{nmol} \mathrm{mol}^{-1}$, respectively, the pyrrole signal reproducibly returns to its baseline value (from $\mathrm{C} 3$ to $\mathrm{C} 2$ ), within the instrumental precision error of $\sim 6 \%$. This shows that the modulation (from $\mathrm{C} 2$ to $\mathrm{C} 3$ ) occurs due to the competition between propane and pyrrole for the available $\mathrm{OH}$ radicals. The evaluated rate coefficient for the reaction of propane with $\mathrm{OH}$ is $(1.1 \pm 0.2) \times 10^{-12} \mathrm{~cm}^{3}$ molecule $^{-1} \mathrm{~s}^{-1}$ (Atkinson et al., 2007). Using Eq. (1), the reactivities due to the propane amounts shown in Fig. 3, were calculated to be $\sim 35.3 \mathrm{~s}^{-1}, 22.5 \mathrm{~s}^{-1}$ and $13.6 \mathrm{~s}^{-1}$, respectively. The breaks in the data plot in Fig. 3 correspond to periods where the instrumental background was measured. The background signal is collected by passing the sampled air over a Pt catalyst kept at $350^{\circ} \mathrm{C}$ to oxidize all the organics. This enables correction for the noise at the measured masses and results in more accurate quantification.

Figure 4 shows the reactivity measured with the CRM (vertical axis) plotted against the reactivity introduced into the glass reactor (horizontal axis) due to several standards in different experiments. In addition to propane, a 19 component hydrocarbon mixture was used as a reactivity standard. The 19 component hydrocarbon mixture is a commercial gas standard (Apel-Riemer Environmental Inc.) and contains numerous compounds spanning four orders of magnitude in $\mathrm{OH}$ reaction rates. These are methanol, acetone, acetaldehyde, hexanal, trans-2-hexenal, methyl ethyl ketone, methyl vinyl ketone, acetonitrile, isoprene, alpha pinene, toluene, benzene, 1,3-dimethyl benzene, 2-methyl furan, 2-pentanone, 1,3,5-trimethyl benzene, 1,2,4,5- tetramethyl benzene, cis2-butene dimethyl sulphide and dimethyl disulphide. Akin to propane, the reactivity due to the standards is calculated using Eq. (1) and using rate coefficients taken from the latest IUPAC recommendations on gas kinetic data evaluation for atmospheric chemistry (Atkinson et al., 2007).

For 1,2,4,5- tetra methyl benzene, no data was available and so its $\mathrm{OH}$ rate coefficient was assumed to be $1 \times 10^{-11} \mathrm{~cm}^{3}$ molecule ${ }^{-1} \mathrm{~s}^{-1}$ (similar to rate coefficients of $\sim 1.3 \times 10^{-11} \mathrm{~cm}^{3}$ molecule ${ }^{-1} \mathrm{~s}^{-1}$ for 1,3-dimethyl benzene and 1,4-dimethyl benzene and $3 \times 10^{-11} \mathrm{~cm}^{3}$ molecule ${ }^{-1} \mathrm{~s}^{-1}$ for 1,3,5-trimethyl benzene). For the 19-component hydrocarbon standard's data shown in Fig. 4, the hydrocarbon concentrations introduced were $\sim 7 \mathrm{nmol} \mathrm{mol}^{-1}$ and $16 \mathrm{nmol}$ $\mathrm{mol}^{-1}$, which are notably higher than the general abundance levels of these VOCs in the atmosphere. The horizontal 


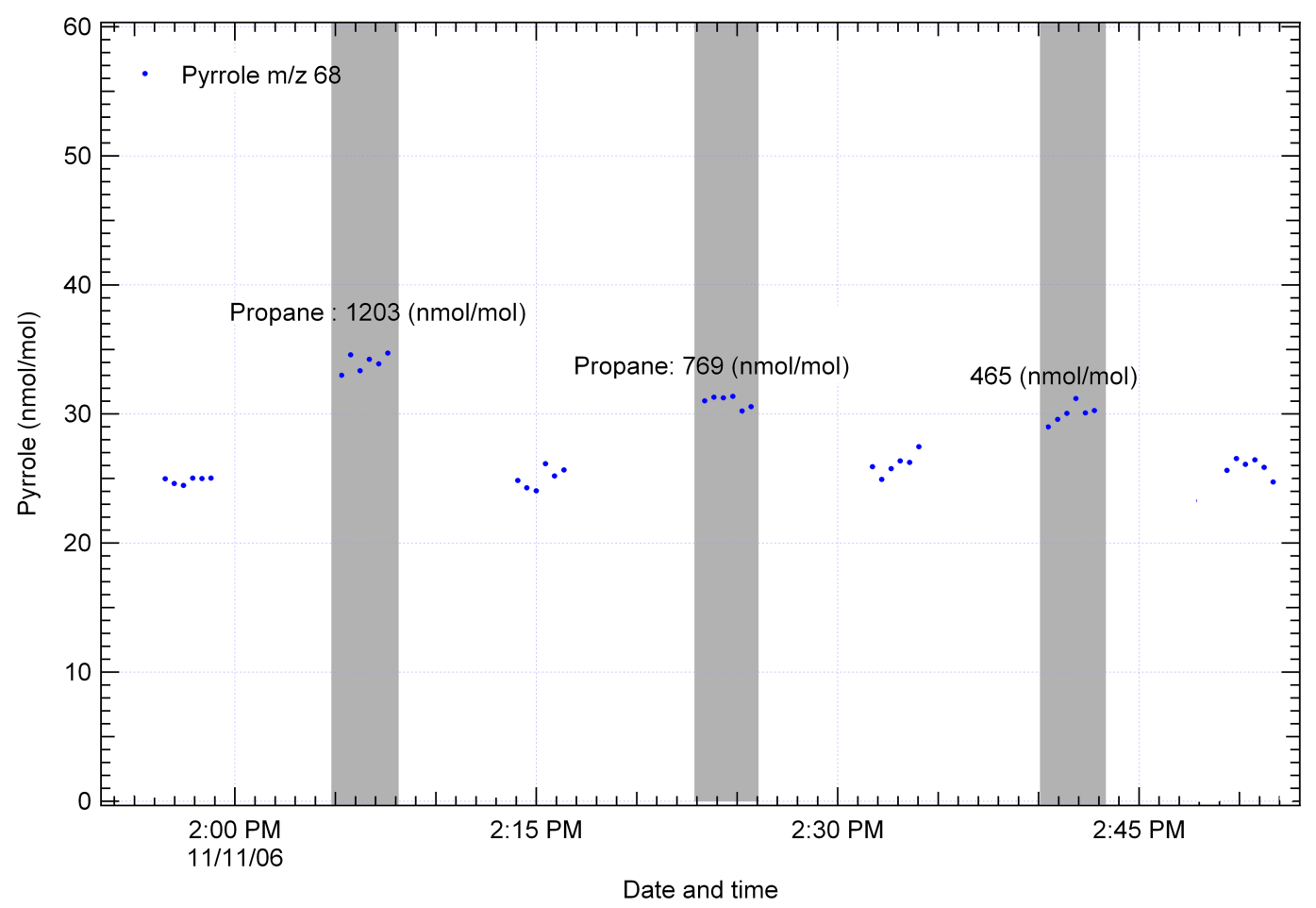

Fig. 3. Example plot showing raw reactivity data and modulations with propane (increase in pyrrole signal). Grey bars indicate the occasions when propane was added to the setup.

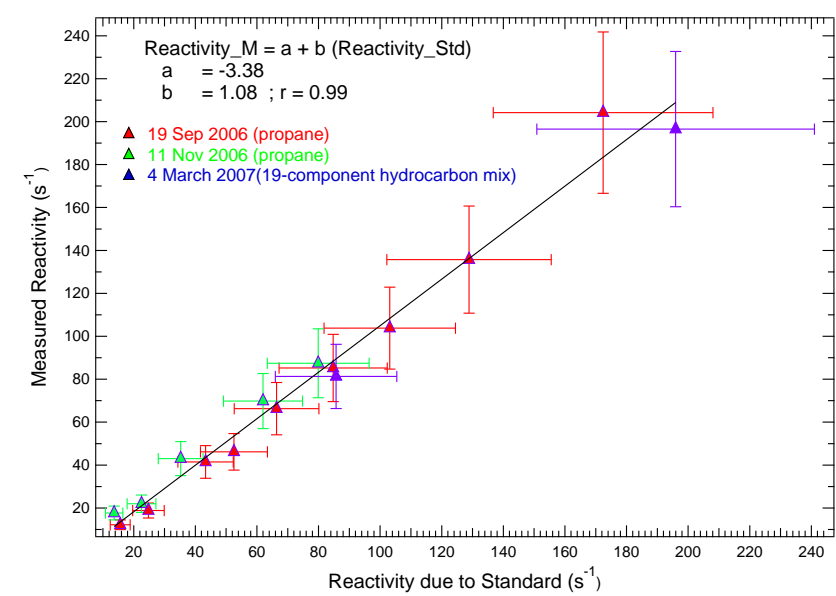

Fig. 4. Method validation and calibration using different standards on different occasions (good reproducibility). Error bars represent the total calculated uncertainty.

error bars in Fig. 4 represent the total uncertainty in the reactivity of the standards, which includes the uncertainties in the VOC+OH-rate coefficient (typically $\sim 15-20 \%$ ), the accuracy of the standard $(\sim 5 \%)$ and the flow fluctuations $(\sim 10 \%)$. The measured reactivity (plotted on the vertical axis in Fig. 4) is obtained by interpolating the measured baseline (corresponding to $\mathrm{C} 2$ in Fig. 4) and applying Eq. (8) to the measured pyrrole signals $\mathrm{C} 1, \mathrm{C} 2$ and $\mathrm{C} 3$.

The vertical error bars $(\sim 20 \%)$ in Fig. 4 represent the total uncertainty in the measured $\mathrm{OH}$ reactivity and include the uncertainty in the pyrrole $+\mathrm{OH}$ rate coefficient $(1.20 \pm 0.16) \times 10^{-10} \mathrm{~cm}^{3}$ molecule ${ }^{-1} \mathrm{~s}^{-1}$, flow fluctuations of the mass flow controllers $(\sim 10 \%)$, uncertainty in the pyrrole standard $(5 \%)$ and instrumental precision error $(\sim 6 \%)$.

Applying the root square propagation of uncertainties due to 1) rate coefficient of pyrrole+OH $(14 \%)$, 2) overall flow fluctuation $(10 \%), 3$ ) uncertainty in value of the pyrrole standard $(5 \%, 4)$ precision error $(6 \%)$, we get an overall error of $18.89 \%$ which is $\sim 20 \%$.

Overall, it can be seen from Fig. 4 that the CRM measurements show excellent linearity $(r=0.99)$ and good accountability (slope of measured reactivity versus reactivity due to standard $=1.08 \pm 0.04$ ) for the reactivity of up to $\sim 196 \mathrm{~s}^{-1}$ due to propane as well as the 19-component hydrocarbon standard. This means that the dynamic range for the reactivity of ambient air (typically diluted in the glass reactor by a factor 1.7-2) would be about 6 to $300 \mathrm{~s}^{-1}$. The intercept of the line in Fig. 4 is negative $(\mathrm{a}=-3.3)$ which indicates that at low reactivity ranges of $<6 \mathrm{~s}^{-1}$ the existing method lacks sensitivity.

Indeed, at low reactivity significant systematic errors can be induced by use of the analytical expression (Eq. 8) which is strictly appropriate only if pseudo-first order conditions exist (i.e. [pyrrole] $\gg[\mathrm{OH}]$ ). Under the experimental conditions 


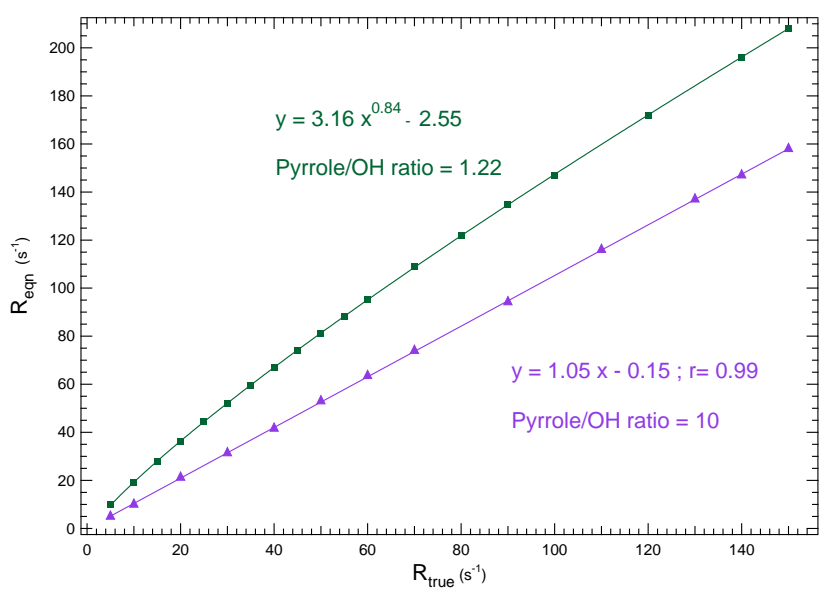

Fig. 5. Plots showing relation between $R_{\text {eqn }}$ and $R_{\text {true }}$ for numerical simulations at [pyrrole]/[OH] ratios of 10 (purple markers) and 1.22 (green markers).

here a significant depletion of pyrrole was however necessary in order to make accurate measurement of $\mathrm{C} 2$ feasible. In fact, even under near pseudo first order conditions ([Pyrrole]/[OH] ratio=10), for sample air having $5 \mathrm{~s}^{-1} \mathrm{OH}$ rate reactivity and $\mathrm{OH}$ radical concentration in the set up of $\sim 2.7 \times 10^{11}$ molecules $\mathrm{cm}^{-3}$, one would have to measure a modulation of $0.2 \mathrm{nmol} \mathrm{mol}^{-1}$ on a baseline (C2) pyrrole signal of $1 \mu \mathrm{mol} \mathrm{mol}^{-1}$, which is not possible with a PTRMS. Only the initial flux of $\mathrm{OH}$ to either pyrrole or air is adequately described by Eq. (8), but the integrated flux to both reactants (i.e. over the entire reaction time for $\mathrm{OH}$ ) may deviate from this if the two pools of reactants (i.e. pyrrole versus air) are depleted at different rates. In order to investigate this, simple numerical simulations (Curtis et al.,1988) were carried out in which an initial concentration of $\mathrm{OH}$ $\left(2.7 \times 10^{12}\right.$ molecules $\left.\mathrm{cm}^{-3}\right)$ was allowed to react firstly with pyrrole only and then with pyrrole and a hydrocarbon with a rate coefficient of $2 \times 10^{-13}$ at different concentrations, to give $\mathrm{OH}$ reactivity between 5 and $150 \mathrm{~s}^{-1}$. Considering the dilution factor for ambient air in the set up, this would correspond to a reactivity range of about 8 to $300 \mathrm{~s}^{-1}$ for ambient air sampling.

The results are summarised in Fig. 5 which plots the reactivity, $R_{\text {eqn }}$, obtained by applying Eq. (8) to the numerical simulations of the pyrrole concentration ( $\mathrm{C} 2$ and $\mathrm{C} 3$ ) after $\mathrm{OH}$ had reacted to zero, versus the true reactivity, $R_{\text {true }}$ (derived from $k_{\mathrm{RH}}$. $[\mathrm{RH}]$; Eq. 1). Two scenarios were considered, one approaching pseudo-first order conditions with $[$ pyrrole] $/[\mathrm{OH}]=10$ and the second one with [pyrrole $] /[\mathrm{OH}]=1.22$. The simulations for near-pseudo-first order conditions (see Fig. 5) provide confirmation of the analytical expression used and return a slope of 1.05. Note that the relationship between $R_{\text {eqn }}$ and $R_{\text {true }}$ is however not perfectly linear, with a maximum deviation of $6 \%$. For the case where [pyrrole] $/[\mathrm{OH}]=1.22$ (also shown in Fig. 5), which is more

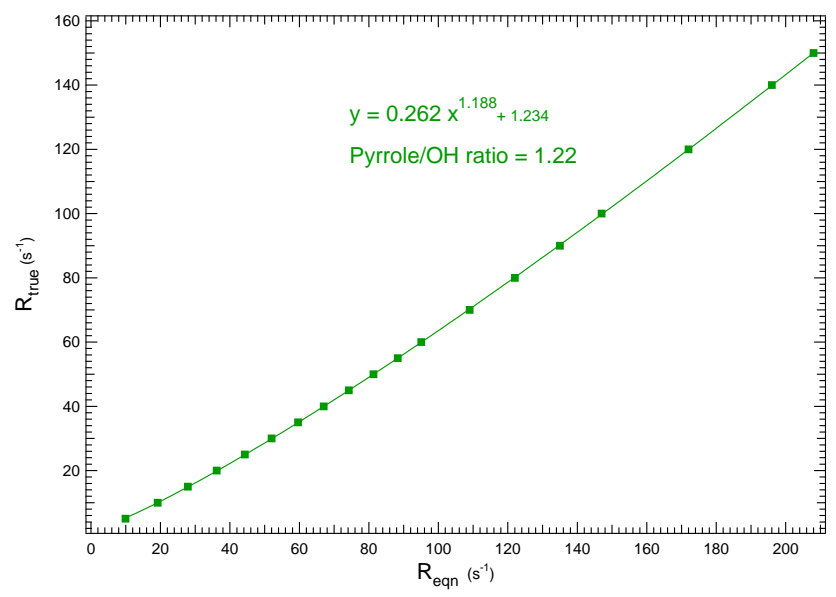

Fig. 6. Plot showing the fitting function obtained between $R_{\text {true }}$ and $R_{\text {eqn }}$ at [pyrrole]/[OH] ratio of 1.22 (the experimental conditions).

relevant for the experiments described here, we obtain the following fitting function:

$R_{\text {eqn }}=3.16 \times R_{\text {true }}^{0.84}-2.55$

This shows that using Eq. (8) under the conditions of [pyrrole $] /[\mathrm{OH}]=1.22$, may cause the measurements to overestimate the $\mathrm{OH}$ reactivity of the analyzed air sample, especially at lower ranges of $\mathrm{OH}$ reactivity. Also, in the real experiment this curvature would not have been observed (e.g. Fig. 4). Nevertheless, as the [pyrrole]/[OH] ratio is known from the experiments $(\mathrm{C} 1 / \mathrm{C} 1-\mathrm{C} 2)$, this simple analysis does enable a correction factor to be derived for the measured data. For conditions typical of the present set of experiments, the correction factor is easily obtained by plotting $R_{\text {true }}$ versus $R_{\text {eqn }}$ as shown in Fig. 6, and we obtain the following correction factor:

$R_{\text {true }}=0.26 R_{\text {eqn }}^{1.19}+1.2$

Applying Eq. (10) to the measured reactivity data in the calibration plot of Fig. 4, we obtain a line with a slope of $0.79 \pm 0.03$ (as shown in Fig. 7). From Fig. 7, it is again obvious that the $\mathrm{OH}$ reactivity measured by the CRM accounts for the introduced air sample's $\mathrm{OH}$ reactivity, within the overall uncertainty of the measurement (20\%). For all measured $\mathrm{OH}$ reactivity data shown hereafter, the correction factor (Eq. 10), has already been applied.

\subsection{Investigation of possible interferences}

Three main potential interferences have been identified while operating the Comparative Reactivity Method in its present configuration. These are: photolysis of pyrrole; recycling of $\mathrm{OH}$ at high $\mathrm{NO}$ due to the $\mathrm{NO}+\mathrm{HO}_{2}$ reaction; and drastic changes in the relative humidity within the set-up when ambient air is sampled. A detailed discussion of each is presented in the following sub-sections. 


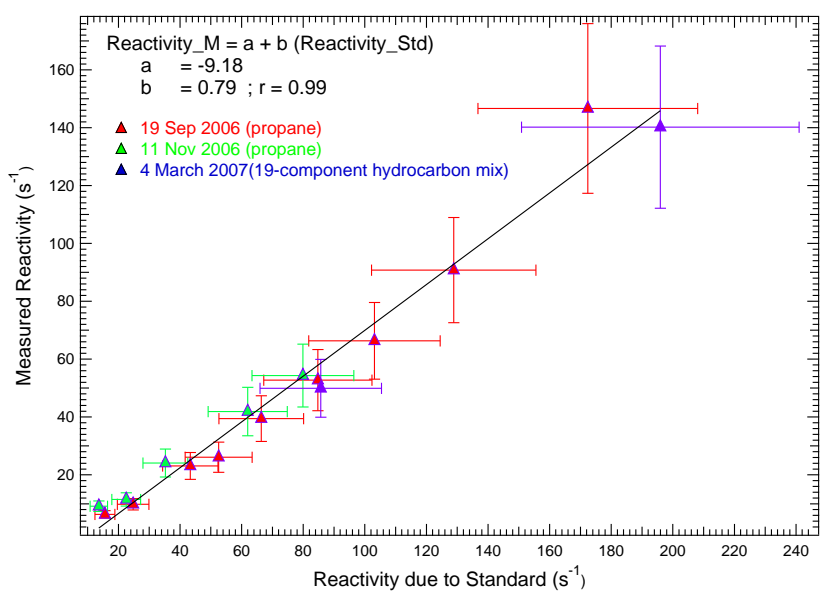

Fig. 7. Method validation and calibration using different standards on different occasions (good reproducibility) after application of the correction factor. Error bars represent the total calculated uncertainty.

\subsubsection{Photolysis of pyrrole}

The pen ray mercury lamp (L.O.T Oriel GmbH and Co. $\mathrm{KG})$, used for producing $\mathrm{OH}$ radicals by photolysis of water vapour at $184.9 \mathrm{~nm}$, also has emission lines at $253.6 \mathrm{~nm}$, $312.5 \mathrm{~nm}, 365 \mathrm{~nm}$ and $435.8 \mathrm{~nm}$. Pyrrole absorbs at some of these wavelengths (Bavia et al., 1976; Cronin et al., 2004 and its photolysis can potentially complicate the reactivity assessment. Switching on the lamp inside the set-up without bubbling the nitrogen through water (so that no $\mathrm{OH}$ radicals are generated) gives the decrease in pyrrole (from $\mathrm{C} 0$ to $\mathrm{C} 1$ ) due to photolysis alone.

In every session of CRM measurements, the $\mathrm{C} 1$ value is obtained experimentally and so the initial amount of pyrrole (corresponding to $\mathrm{C} 1$ ), which is available for reaction with $\mathrm{OH}$, is known accurately. Using $\mathrm{C} 1$ instead of $\mathrm{C} 0$ is valid provided that the photolytic loss of pyrrole is not significantly influenced by addition of water vapour. As $\mathrm{H}_{2} \mathrm{O}$ does not absorb strongly at the $254.6 \mathrm{~nm} \mathrm{Hg}$ line, which is mainly responsible for pyrrole photolysis, this is a reasonable assumption. Photolysis of pyrrole in our set-up (can be up to 25\%) is a significant interference if it is not taken into account. However, by measuring and hence knowing its contribution to the observed decrease in the pyrrole signal, when the lamp is switched on in the presence of moist $\mathrm{N}_{2}$ for $\mathrm{OH}$ production ensures that this interference is adequately quantified and hence has negligible influence on the measurements. This is also borne out by the good agreement obtained using reactivity standards as mentioned earlier.

\subsubsection{Recycling of $\mathrm{OH}$ due to $\mathrm{HO}_{2}+\mathrm{NO}$}

The pen-ray mercury lamp produces $\mathrm{OH}$ radicals by the photolysis of water vapour at atmospheric pressure in the follow-

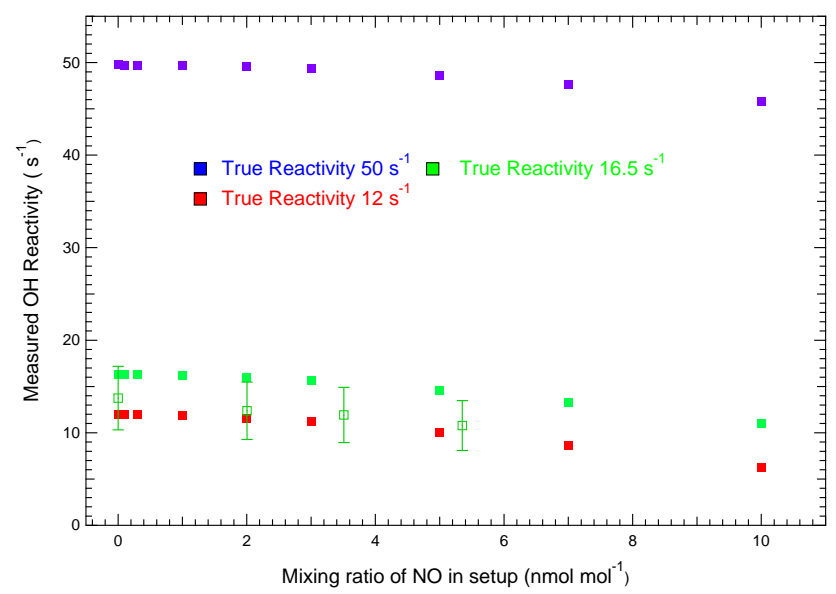

Fig. 8. Results of the experimental (open green markers) and numerical (closed markers: red, green and purple) NO sensitivity study to determine its impact on the CRM measurements.

ing manner

$\mathrm{H}_{2} \mathrm{O} \stackrel{184.9 \mathrm{~nm}}{\longrightarrow} \mathrm{OH}+\mathrm{H}$

While the above step is performed only in a flow of $\mathrm{N}_{2}$, zero air containing oxygen $\left(\mathrm{O}_{2}\right)$ enters the glass reactor through arm A (see Fig. 2), so that $\mathrm{HO}_{2}$ is also rapidly produced within the glass reactor by the following reaction:

$\mathrm{H}+\mathrm{O}_{2}+\mathrm{M} \longrightarrow \mathrm{HO}_{2}+\mathrm{M}$

If $\mathrm{NO}$ is present in the sampled ambient air, it can recycle $\mathrm{OH}$ radicals:

$\mathrm{NO}+\mathrm{HO}_{2}{ }^{k=8.8 \times 10^{-12}} \stackrel{\mathrm{cm}^{3}}{\longrightarrow} \operatorname{molec}^{-1} \mathrm{~s}^{-1} \mathrm{OH}+\mathrm{NO}_{2}$

Figure 8 shows the measured $\mathrm{OH}$ reactivity (vertical axis; open green markers) for different amounts of NO in the setup (horizontal axis) while sampling air containing propane $\left(\sim 16.5 \mathrm{~s}^{-1}\right.$ of reactivity; $558 \mathrm{nmol} \mathrm{mol}{ }^{-1}$ propane). Note that even at such high values of propane in the introduced air sample ( $\sim 16.5 \mathrm{~s}^{-1}$ of reactivity; $558 \mathrm{nmol} \mathrm{mol}^{-1}$ propane), the measured $\mathrm{OH}$ reactivity is not affected significantly (that is, the change is within the measurement uncertainty) for added $\mathrm{NO}$ concentrations of up to $\sim 3.5 \mathrm{nmol} \mathrm{mol}^{-1}$. Above $5 \mathrm{nmol} \mathrm{mol}^{-1}$ of $\mathrm{NO}$ in the setup, however, the change in the measured $\mathrm{OH}$ reactivity due to reaction with the recycled $\mathrm{OH}$ was non-linear and caused significant interference in the CRM measurements, so that the entire modulation (C3C2) was suppressed (data not plotted in Fig. 8). The numerical simulation for the same value of introduced reactivity $\left(16.5 \mathrm{~s}^{-1}\right)$ is also shown in Fig. 8 (the closed green markers) and are in good agreement with the profile of the measurements (open green markers) up to $\sim 3.5 \mathrm{nmol} \mathrm{mol}^{-1}$. This numerical simulation included the complete propane degradation mechanism (to end products $\mathrm{CO}_{2}$ and $\mathrm{H}_{2} \mathrm{O}$ ) (Atkinson et al., 2007) and, by neglecting reactions of $\mathrm{RO}_{2}$ with 


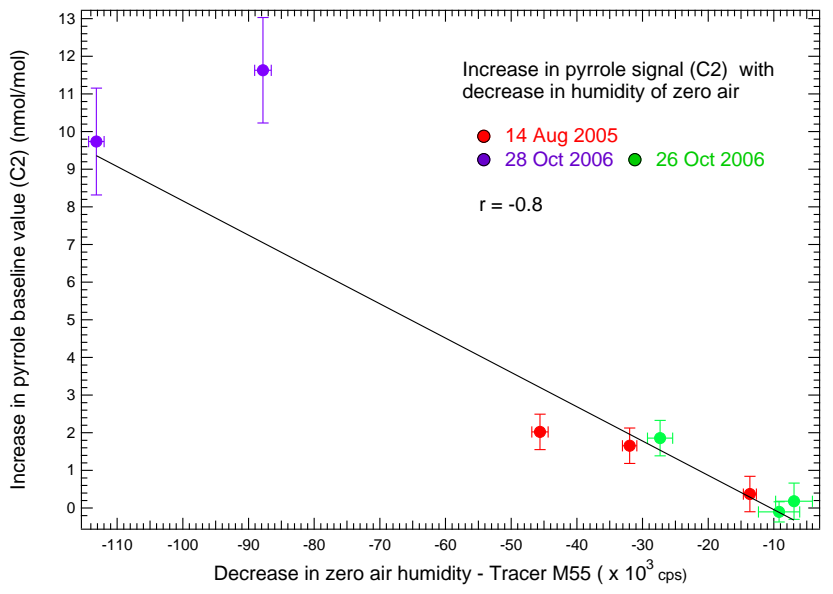

Fig. 9. Changes in the measured pyrrole signal due to changes in relative humidity within the glass reactor

themselves or with $\mathrm{HO}_{2}$, represents the worst case scenario in which the rate of reaction of $\mathrm{HO}_{2}$ with $\mathrm{NO}$ is optimized. Beyond $3.5 \mathrm{nmol} \mathrm{mol}^{-1}$ of NO in the setup, while the simulation also shows more suppression in the measured $\mathrm{OH}$ reactivity, the scale of change is not the same as that observed for the measurements (measured $\mathrm{OH}$ reactivity tends to zero at $10 \mathrm{nmol} \mathrm{mol}^{-1}$ of $\mathrm{NO}$ in the experiments while the simulation shows only $\sim 70 \%$ change, from $16.5 \mathrm{~s}^{-1}$ to $5 \mathrm{~s}^{-1}$; Fig. 8). Further simulations at $12 \mathrm{~s}^{-1}$ (red markers in Fig. 8) and $50 \mathrm{~s}^{-1}$ (purple markers in Fig. 8) of $\mathrm{OH}$ reactivity confirm the same trend of underestimation of measured $\mathrm{OH}$ reactivity at $\mathrm{NO}>5 \mathrm{nmol} \mathrm{mol}^{-1}$ in the setup.

\subsubsection{Humidity difference between zero air and ambient air}

If the zero air used in lieu of ambient air to determine the pyrrole baseline signal (corresponding to $\mathrm{C} 2$ in Fig. 1) differs substantially in humidity from that of the sampled ambient air, then the amount of $\mathrm{OH}$ radicals generated within the glass reactor might change, causing artefacts in the measured $\mathrm{C} 2$ and $\mathrm{C} 3$ pyrrole signals. When the zero air is drier than the ambient air entering the glass reactor, more $\mathrm{OH}$ radicals may be produced while sampling/modulating with ambient air due to photolysis of the 'extra' water vapour present in the sampled ambient air. As a result, there can be a suppression of the measured pyrrole signal (C3) causing the measurements to underestimate the actual reactivity. Conversely, if the zero air is wetter than the sampled ambient air, less $\mathrm{OH}$ radicals may be available for reaction with pyrrole during the sampling of ambient air, leading to an enhancement of the measured pyrrole signal (C3) and resulting in measurements that may overestimate the actual $\mathrm{OH}$ reactivity.

To ascertain how significant this interference might be, the zero air flowing into the set-up was humidified to different degrees by mixing varying amounts of wet and dry zero air prior to its introduction into the glass reactor through arm
A (see Fig. 2). Then, the variation in the pyrrole baseline (signal C2 in Fig. 1) was monitored for different degrees of humidified zero air. The humidity of the glass reactor air is tracked using mass 55 (cluster ion $\mathrm{H}_{3} \mathrm{O}^{+}\left(\mathrm{H}_{2} \mathrm{O}\right)_{2}$ ), with the PTR-MS, similar to the approach of Ammann et al. (2006). Figure 9 shows the results, with the increase in the pyrrole signal (vertical axis) plotted against the corresponding decrease in humidity (horizontal axis). It is evident that repeating the experiment on different occasions which involved reassembling the whole set up and slightly different flows (see data for 14 August 2005 and 26 October 2006 in Fig. 9) produces a consistent trend line.

The data in the top left hand corner of Fig. 9 were obtained under the extreme condition of measuring the change in the pyrrole signal $(\mathrm{C} 2)$ while using saturated zero air $(\sim 90 \%)$ and dry zero air, taken directly from the bottle. Figure 9 also shows that for changes in mass 55 (humidity tracer) of up to $\sim 20000$ counts per second (cps) the change in the pyrrole signal is $<1 \mathrm{nmol} \mathrm{mol}^{-1}$, which is within the precision error of the PTR-MS. Therefore, while conducting ambient air reactivity measurements, the diluting zero air is humidified to lie within the $20000 \mathrm{cps}$ range of the mass 55 signal observed for ambient air. So, while drastic changes in humidity can cause a significant interference, care is taken to match the mixing gases close to the ambient humidity and thereby significant interferences are avoided.

\subsection{Field deployment and first CRM results of ambient air $\mathrm{OH}$ reactivity}

To test the capability and performance of the technique under markedly different ambient conditions, measurements were conducted first in the urban atmosphere of Mainz, Germany, and then in the tropical rainforest air of Suriname in August and October 2005, respectively.

\subsubsection{Total $\mathrm{OH}$ reactivity of Mainz air: urban environment}

Figure 10 shows the diel $\mathrm{OH}$ reactivity profile for Mainz air, measured with the CRM technique from 18-20 August 2005. Ambient air was sampled outside our laboratory $\left(49^{\circ} 59^{\prime} \mathrm{N}\right.$, $\left.8^{\circ} 14^{\prime} \mathrm{E}\right)$ at the Max Planck Institute for Chemistry in Mainz, circa $8 \mathrm{~m}$ above the ground. Just outside the laboratory there is an undergrowth of bushes and plants. The sampled ambient air was introduced directly into the CRM glass reactor using $\sim 12 \mathrm{~m}$ long, $1 / 2$ inch (o.d.) Teflon tubing, using a VOC sampling pump (Laboport N86-KN18). The inlet residence time for the ambient air was $<20 \mathrm{~s}$ and the measurement frequency was $0.025 \mathrm{~Hz}$. During the measurements, NO in Mainz air was typically less than $1.5 \mathrm{nmol} \mathrm{mol}^{-1}$ (Landesamt für Umwelt, Wasserwirtschaft und Gewerbeausicht Rheinland-Pfalz). The average value of the total $\mathrm{OH}$ reactivity of Mainz air was $\sim 10.4 \mathrm{~s}^{-1}$. OH reactivity was observed to be highest during the afternoon (13:00 L.T.), reaching peak values of $\sim 18 \pm 4 \mathrm{~s}^{-1}$, while lowest values 


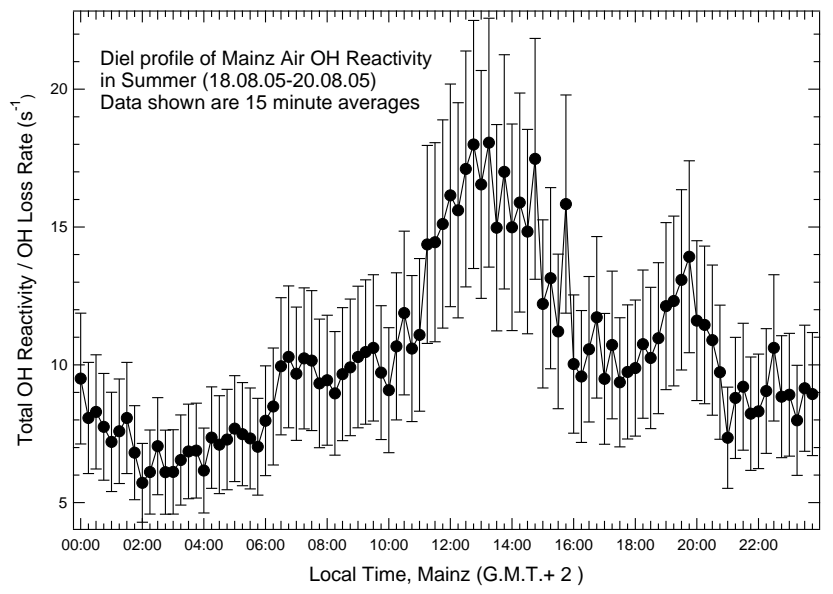

Fig. 10. Diel mean profile (black circles) of the total OH Reactivity of Mainz (urban site) air measured during summer (August 2005) with the CRM instrument.

$\left(\sim 6 \pm 3 \mathrm{~s}^{-1}\right)$ were observed early in the morning between 02:00 to 04:00 L.T.

\subsubsection{Total OH reactivity of Suriname rainforest air: forest environment}

Figure 11 shows $\mathrm{OH}$ reactivity measurements of rainforest air at the peak of diel emissions. The measurements were taken in the nature reserve of Brownsberg $\left(4^{\circ} 56^{\prime} \mathrm{N}, 55^{\circ} 10^{\prime} \mathrm{W}\right.$, $512 \mathrm{~m}$ a.s.1.) in Suriname, within the canopy at about $35 \mathrm{~m}$ above the ground. Details about the sampling methodology along with the site description are given elsewhere (Sinha et al., 2007b; Williams et al., 2007). Ambient forest air reactivity was measured for almost $2 \mathrm{~h}$ on 6 October 2005 before the PTR-MS broke down. Earlier, from 2 to 5 October 2005, the PTR-MS was used to measure ambient air directly (without reactivity measurements) to determine diel emission profiles for VOCs such as acetone (mass 59), acetaldehyde (mass 45), isoprene (mass 69) and the isoprene oxidation products, methyl vinyl ketone and methacrolein (detected collectively at mass 71). The calculated diel reactivity profile derived from the ambient air PTR-MS measurements of these species is shown on the right vertical axis of Fig. 11. The CRM reactivity measurements shown in Fig. 11 were taken when forest air seemed to have maximum $\mathrm{OH}$ reactivity, as they coincide with the peak of diel forest emissions. The average of all the OH reactivity measurements $\left(\sim 2 \mathrm{~h}\right.$ of data) was circa $53 \mathrm{~s}^{1}$, with a peak $\mathrm{OH}$ reactivity of approximately $72 \pm 18 \mathrm{~s}^{-1}$.

\section{Discussion}

The results shown here demonstrate that a new and promising online technique capable of directly measuring the total $\mathrm{OH}$ reactivity of ambient air has been developed. Using pyrrole and a PTR-MS, as the reagent molecule and detector, respectively, the dynamic range of the technique in its existing configuration is about 6 to $300 \mathrm{~s}^{-1}$ for ambient air. At $\mathrm{C} 1, \mathrm{C} 2$ and $\mathrm{C} 3$ values of $120 \mathrm{nmol} \mathrm{mol}{ }^{-1}, 20 \mathrm{nmol} \mathrm{mol}^{-1}$ and $1.5 \mathrm{nmol} \mathrm{mol}^{-1}$, respectively, the measured reactivity using Eq. (8) is $\sim 5.9 \mathrm{~s}^{-1}$. Applying the correction factor in Eq. (10) this corresponds to true reactivity of $\sim 3.3 \mathrm{~s}^{-1}$ and allowing for the dilution factor of 1.7 within the set up, this implies $\sim 6 \mathrm{~s}^{-1}$ of reactivity for the sampled ambient air. The overall uncertainty of the measurements is typically around $25 \%$. At lower ambient air reactivities $\left(<\operatorname{circa} 8 \mathrm{~s}^{-1}\right)$, the uncertainty can be up to $\pm 50 \%$. This is sensitive enough to constrain the $\mathrm{OH}$ reactivity $(\mathrm{OH}$ sink) and test for missing $\mathrm{OH}$ reactants during field campaigns (when $\mathrm{OH}$ reactivity $>8 \mathrm{~s}^{-1}$ ). The technique performs well with propane and mixed hydrocarbon standards and accounts for the introduced reactivity within the measurement uncertainty. While the slope of the trend line derived from the calibration experiments (Fig. 4) tended to slightly overestimate the true reactivity by circa $8 \%$, the trend line obtained by applying a model correction factor to the same data (Fig. 7), tended to underestimate the true reactivity by circa $20 \%$. Note however that both the simulation and the experiments lie within $20 \%$ of the true reactivity due to the different standards.

While major potential interferences have been investigated in Sect. 4.3, other minor interferences have also been considered. Ambient air VOCs which absorb in the UV region may undergo photolysis within the set up. However, the fact that the calibration line due to the 19 component hydrocarbon standard (containing VOCs such as acetaldehyde, hexanal and aromatics and methyl vinyl ketone, which absorb UV light and are introduced at concentrations of 7 to $17 \mathrm{nmol}$ $\mathrm{mol}^{-1}$ ), falls on the same trend line as that of propane (see Fig. 4), suggests that this is not a significant effect. To test for secondary chemistry along the reaction length, and the sensitivity to slight change of flows $\left(\sim 20 \mathrm{ml} \mathrm{minute}^{-1}\right)$ the PTR-MS probe (inlet D of the glass reactor; Fig. 2) was placed at different points along the length of the glass reactor. However, no noticeable change in the measured pyrrole signal was observed. This simple test is also applied in the field, while sampling ambient air to investigate the influence of secondary chemistry within the glass reactor. It is also worth mentioning that the lifetime of $\mathrm{OH}$ radicals within the glass reactor set up is always $<4 \mathrm{~ms}$.

Ozone is also produced within the glass reactor by photolysis of $\mathrm{O}_{2}$ due to the $184.9 \mathrm{~nm}$ lamp emission line. Moreover the ratio of $\mathrm{O}_{3} / \mathrm{OH}$ in our glass reactor set up is similar to that found in ambient air $\left(10^{3}\right)$. However, the ozone (produced at $\mu \mathrm{mol} \mathrm{mol}^{-1}$ level) hardly affects the pyrrole signal since the pyrrole $+\mathrm{O}_{3}$ reaction rate $\left(k_{\mathrm{O} 3}+\right.$ pyrrole $=1.57 \times 10^{-17} \mathrm{~cm}^{3}$ molecule ${ }^{-1} \mathrm{~s}^{-1}$ (Atkinson et al., 1984) is several orders of magnitude slower than the reaction rate with $\mathrm{OH}$ radicals. With regard to the reactions of $\mathrm{HO}_{\mathrm{x}}$ with $\mathrm{O}_{3}$ in the set up, the contribution of the $\mathrm{HO}_{\mathrm{x}}$ and $\mathrm{O}_{3}$ (e.g. $\mathrm{HO}_{2}+\mathrm{O}_{3}$ ) reactions to the production or destruction of $\mathrm{OH}$ radicals within the setup does not change appreciably in the presence of ambient air 


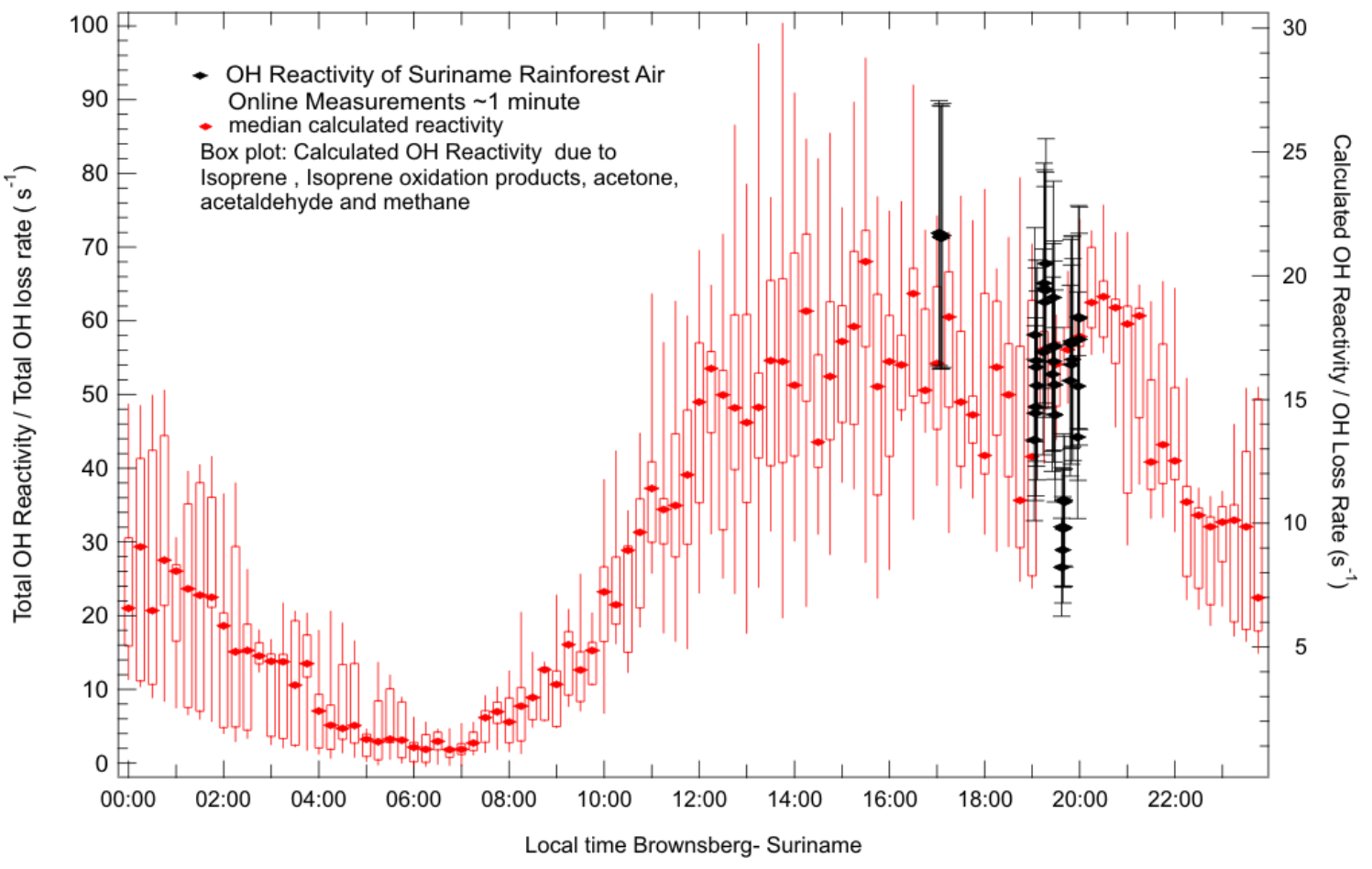

Fig. 11. Total $\mathrm{OH}$ reactivity measurements (black markers) of rainforest air in Brownsberg, Suriname along with diel median profile of calculated $\mathrm{OH}$ reactivity (red markers) due to isoprene, mvk, methacrolein, acetone and acetaldehyde), obtained during the dry season in October 2005 .

due to their low levels of ambient abundance ( $\mathrm{ppb}$ for $\mathrm{O}_{3}$ and ppt for $\mathrm{HO}_{\mathrm{x}}$ ) when compared with the levels already within the set up (ppm for $\mathrm{O}_{3}$ and $\mathrm{ppb}$ for $\mathrm{HO}_{\mathrm{x}}$ ). It is also worth mentioning that reactions involving the $\mathrm{OH}$ radical and ambient $\mathrm{HO}_{2}, \mathrm{O}_{3}$ are not important because of the very short lifetime of $\mathrm{OH}$ with respect to pyrrole (less than $4 \mathrm{~ms}$ ). When terpenes and sesquiterpenes are present in ambient air, they can react with $\mathrm{O}_{3}$ within the glass reactor and recycle $\mathrm{OH}$ (Paulson et al., 1999; Hasson et al., 2003). Also, some $\mathrm{RO}_{2}$ reactions with $\mathrm{HO}_{2}$ may also generate $\mathrm{OH}$ (Hasson et al., 2004), again potentially affecting the reactivity measurement. Note however, that the recycled $\mathrm{OH}$ due to ozonolysis of these reactive alkenes and the Hasson reactions within the glass reactor is negligible compared to the high $\mathrm{OH}$ radical concentrations $\left(\sim 2.15 \times 10^{12}\right.$ molecules $\left.\mathrm{cm}^{-3}\right)$ generated insitu by photolysis of water vapour at $184.9 \mathrm{~nm}$ and $\mathrm{O}_{3}$ photolysis at $254 \mathrm{~nm}$, which also produces $\mathrm{OH}$ by the $\mathrm{O}\left({ }^{1} \mathrm{D}\right)+\mathrm{H}_{2} \mathrm{O}$ reaction. For the same reason, the CRM method may actually perform better under such ambient air conditions (of highly reactive terpenes in ambient air) than the LIF based method. This is because the regenerated $\mathrm{OH}$ radicals may mask the actual $\mathrm{OH}$ decay rate within the LIF instrument's flow reactor and cause an underestimation of the actual measured decay rate and $\mathrm{OH}$ reactivity.

The NO sensitivity studies have shown that in the existing configuration of CRM high NO in sampled air causes interference. We found significant interference at $\mathrm{NO}>5 \mathrm{nmol}$ $\mathrm{mol}^{-1}$ in the setup for propane at $\sim 16.5 \mathrm{~s}^{-1}$ reactivity, and numerical simulations for $50 \mathrm{~s}^{-1}$ of $\mathrm{OH}$ reactivity in the set up (corresponding to $100 \mathrm{~s}^{-1}$ of $\mathrm{OH}$ reactivity for ambient air due to the dilution factor of 2) also indicate that the interference is not significant for $\mathrm{NO}<5 \mathrm{nmol} \mathrm{mol}^{-1}$ in the setup. In this respect, it would be useful and interesting to compare the CRM technique with the LIF based reactivity measurement technique to test for systematic offsets between the two analytical approaches. It is worth mentioning here that the LIF based methods can measure $\mathrm{OH}$ reactivity in the sub $6 \mathrm{~s}^{-1}$ range, provided NO is not too high. Under our experimental conditions, it is likely that high $\mathrm{NO}\left(>10 \mathrm{nmol} \mathrm{mol}^{-1}\right)$ in ambient air might cause the measurements to underestimate the actual reactivity. Thus, low $\mathrm{NO}_{\mathrm{x}}$ environments such

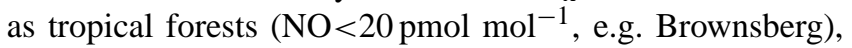
moderately polluted cities $\left(\mathrm{NO}<10 \mathrm{nmol} \mathrm{mol}^{-1}\right)$ and pristine marine environments appear to be ideal sites for the deployment of the existing CRM instrument.

Further modifications to improve the sensitivity, precision and automation of the instrument and to minimize/remove interferences can proceed now that the first validation is complete. For example, a mercury pen-lamp equipped with an interference filter to transmit only the $184.9 \mathrm{~nm}$ line, would significantly reduce photolysis related interferences. $\mathrm{OH}$ sources that are not $\mathrm{HO}_{2}$ sources exist and may help in improving the current system (e.g. photolysis of $\mathrm{H}_{2} \mathrm{O}_{2}, \mathrm{~F}+\mathrm{H}_{2} \mathrm{O}$, photolysis of $\mathrm{N}_{2} \mathrm{O}$ followed by the reaction of $\mathrm{O}^{1} \mathrm{D}$ with 
Table 1. Summary of ambient air $\mathrm{OH}$ reactivity measurements.

\begin{tabular}{|c|c|c|c|}
\hline Site & Ave/Med ${ }^{+}\left(s^{-1}\right)$ & $\operatorname{Max}\left(\mathrm{s}^{-1}\right)$ & Reference \\
\hline Nashville,TN, USA & 11 & 25 & Kovacs et al. (2003) \\
\hline New York City, USA & 19 & 50 & Ren et al. (2003) \\
\hline Tokyo, Japan & 40 & 85 & Sadanaga et al. (2005) \\
\hline M.C.M.A, Mexico & 33 & 200 & Shirley et al. (2005) \\
\hline Pine forest, USA & - & 13 & Di Carlo et al. (2004) \\
\hline Mainz, Germany & 10.4 & 18 & This work \\
\hline Rainforest, Suriname & $53^{\S}$ & $72^{\S}$ & This work \\
\hline
\end{tabular}

$+=$ average was used when median was not available.

$\S=$ measurements period was at peak of diel emissions.

water). The existing sampling strategy for introducing ambient air into the glass reactor, which uses a VOC sampling Teflon pump (Laboport N86-KN18), could also be modified so that the ambient air enters the set-up directly without going through a pump. This would help to minimize the loss of sticky reactive VOCs, which may contribute significantly to $\mathrm{OH}$ reactivity. While we have used the reagent and detector system of pyrrole and a PTR-MS, respectively, in principle it should be possible to apply the Comparative Reactivity Concept to other suitable reagent molecules (e.g. labeled isotopes of isoprene) and detectors (e.g. fast GC-MS systems). Other reagent molecules, which have a smaller rate coefficient than that of pyrrole with $\mathrm{OH}$ may also afford better sensitivity at lower ranges of ambient air $\mathrm{OH}$ reactivity.

The instrument has been successfully deployed in the field to measure the total $\mathrm{OH}$ reactivity of ambient air in the contrasting environments of Mainz (urban), Germany and Brownsberg (rainforest air), Suriname. The measurements indicated that at the peak of diel emissions, Suriname forest air was 4 times more reactive than the urban air of Mainz $\left(72 \mathrm{~s}^{-1}\right.$ compared to $18 \mathrm{~s}^{-1}$ ). The total $\mathrm{OH}$ reactivity measurements for Mainz air lie well within the range of total $\mathrm{OH}$ reactivity measurements reported in literature for urban air sites. Table 1 presents a summary of ambient air $\mathrm{OH}$ reactivity measurements from urban and forest sites. Kovacs et al. (2003) reported ambient air OH reactivity values of $11-19 \mathrm{~s}^{-1}$ at Nashville, TN, USA. In the same campaign, a comparison of the measured $\mathrm{OH}$ reactivity and the calculated reactivity due to the measured reactants (70 VOCs), showed that on average, the measured $\mathrm{OH}$ reactivity was 1.45 times higher (Martinez et al., 2003). Using laser induced fluorescence based techniques, maximum $\mathrm{OH}$ reactivity values of $50 \mathrm{~s}^{-1}$ in New York City (Fig. 8 in Ren et al., 2003), $85 \mathrm{~s}^{-1}$ in suburban Tokyo (Sadanaga et al., 2004a; Sadanaga et al., 2005; Yoshino et al., 2006), and $200 \mathrm{~s}^{-1}$ in Mexico city (Fig. 9 in Shirley et al., 2006) have been observed.

To our knowledge, the ambient air $\mathrm{OH}$ reactivity measurements from Brownsberg are the first total $\mathrm{OH}$ reactivity measurements from a tropical rainforest site, an ecosystem that is known for strong biogenic emissions (Karl et al., 2004; Goldstein and Galbally, 2007). Di Carlo et al. (2004) observed missing $\mathrm{OH}$ reactivity in a mixed transition forest consisting of northern hardwood, aspen and white pine in north Michigan. Our limited $\mathrm{OH}$ reactivity measurements from Brownsberg also indicate that a significant fraction of important $\mathrm{OH}$ reactive compounds are likely missed in conventional measurements at forest sites (see Fig. 11), since isoprene, isoprene oxidation products, acetone and acetaldehyde make up only $\sim 35 \%$ of the measured sink. In future studies, it will be interesting to measure a more comprehensive suite of VOCs and other OH-reactive species such as $\mathrm{NO}_{2}$ and $\mathrm{SO}_{2}$, together with direct $\mathrm{OH}$ reactivity measurements to better understand the budget of $\mathrm{OH}$ sinks. Rate constants for the reaction of $\mathrm{OH}$ with almost all measured ambient VOCs are known. By summing up the calculated reactivity due to all the measured VOCs (i.e. summation of VOC concentration times its rate coefficient) and comparing it with the direct $\mathrm{OH}$ reactivity measurement, one can additionally examine the reactive carbon budget and assess to what extent the individually measured VOCs account for the total $\mathrm{OH}$ reactivity.

\section{Conclusions}

This study has shown that the Comparative Reactivity Method (CRM) can be applied for measurements of the total $\mathrm{OH}$ reactivity of ambient air. Applying the CRM concept to the reagent and detector system of pyrrole and a PTRMS, respectively, a new online measurement technique with a dynamic range of about 6 to $300 \mathrm{~s}^{-1}$ for ambient air and accuracy of $\pm 25 \%$ has been developed. Sensitivity studies (involving changing parameters) have been carried out, and high NO (>10 nmol mol${ }^{-1}$ ) in ambient air has been identified as the major interference. Therefore low $\mathrm{NO}_{\mathrm{x}}$ environments such as remote forest sites and marine environments are ideal for deploying the new instrument, and improvements in the existing set up are needed for conducting measurements in strongly $\mathrm{NO}_{\mathrm{x}}$ polluted environments. 
Moderately polluted Mainz air measurements $(\mathrm{NO} \leq 1.5 \mathrm{nmol}$ $\mathrm{mol}^{-1}$ ) are consistent with $\mathrm{OH}$ reactivity measurements reported previously for urban air. Our measurements from the tropical rainforest (for which no other data exists) indicate that a significant fraction of $\mathrm{OH}$ reactive species is missed in current measurements. Further $\mathrm{OH}$ reactivity measurements, combining comprehensive measurements of VOCs and other $\mathrm{OH}$ reactive species are needed to clarify whether sinks are currently underestimated in forest environments and to constrain the budget of reactive VOCs.

Finally, several measurement groups routinely employ proton transfer reaction mass spectrometers and gas chromatography detectors for measuring VOCs in ambient air, during field campaigns. It would be relatively easy and economical to integrate a glass reactor and employ the CRM based technique proposed in this study with these detectors for direct quantification of the $\mathrm{OH}$ sink, using either pyrrole or another suitable molecule. One of the future objectives will also be to compare the newly developed CRM based instrument with the existing more comprehensive laser induced fluorescence (LIF) based reactivity measurement technique, to test for systematic offsets between the two analytical approaches. Hopefully, this study will stimulate further efforts in the application of the Comparative Reactivity Method for ambient air $\mathrm{OH}$ reactivity measurements.

Acknowledgements. Special thanks to S. Jung for helping with her expertise in glass blowing and furnishing the requested myriad glassware and reactors, sometimes even at very short notice. K. Simon is appreciated for expediting delivery of the custom ordered hydrocarbon standards. V. Sinha acknowledges the financial support rendered by the Max Planck Society. Last but certainly not the least, we thank all the members of the ORSUM group, in particular T. Kluepfel and T. Custer who have facilitated the successful accomplishment of this work.

Edited by: R. Cohen

\section{References}

Ammann, C., Brunner, A., Spirig, C., and Neftel, A.: Technical note: Water vapour concentration and flux measurements with PTR-MS, Atmos. Chem. Phys., 6, 4643-4651, 2006, http://www.atmos-chem-phys.net/6/4643/2006/.

Atkinson, R., Aschmann, S. M., Winer, A. M., and Carter, W. P. L.: Rate Constants for the Gas-Phase Reactions of $\mathrm{OH}$ Radicals and $\mathrm{O}_{3}$ with Pyrrole at 295+/-1k and Atmospheric-Pressure, Atmos. Environ., 18, 2105-2107, 1984.

Atkinson, R., Baulch, D. L., Cox, R. A., Crowley, J. N., Hampson, R. F., Hynes, R. G., Jenkin, M. E., Kerr, J. A., Rossi, M. J. and Troe, J.: IUPAC Subcommittee for gas kinetic data evaluation, Evaluated kinetic data: http://www.iupac-kinetic.ch.cam.ac.uk/, 2007.

Bavia, M., Bertinelli, F., Taliani, C., and Zauli, C., ElectronicSpectrum of Pyrrole in Vapor and Crystal: Mol. Phys., 31, 479489, 1976.
Carslaw, N., Creasey, D. J., Heard, D. E., Jacobs, P. J., Lee, J. D., Lewis, A. C., McQuaid, J. B., Pilling, M. J., Bauguitte, S., Penkett, S. A., Monks, P. S., and Salisbury, G.: Eastern Atlantic Spring Experiment 1997 (EASE97) - 2. Comparisons of model concentrations of $\mathrm{OH}, \mathrm{HO}_{2}$, and $\mathrm{RO}_{2}$ with measurements, J. Geophys. Res.-Atmos., 107,4190, doi:10.1029/2001JD001568, 2002.

Cronin, B., Nix, M. G. D., Qadiri, R. H., and Ashfold, M. N. R.: High resolution photofragment translational spectroscopy studies of the near ultraviolet photolysis of pyrrole, Phys. Chem. Chem. Phys., 6, 5031-5041, 2004.

Curtis, A. R. and Sweetenham, W. P.: Facsimile/Chekmat Users Manual, AERE Report R-12805, Her Majesty's Stationary Office, England, 1988.

de Gouw, J. and Warneke, C.: Measurements of volatile organic compounds in the earths atmosphere using proton-transferreaction mass spectrometry, Mass Spectrom. Rev., 26, 223-257, 2007.

Di Carlo, P., Brune, W. H., Martinez, M., Harder, H., Lesher, R., Ren, X. R., Thornberry, T., Carroll, M. A., Young, V., Shepson, P. B., Riemer, D., Apel, E., and Campbell, C.: Missing OH reactivity in a forest: Evidence for unknown reactive biogenic VOCs, Science, 304, 722-725, 2004.

Goldstein, A. H., McKay, M., Kurpius, M. R., Schade, G. W., Lee, A., Holzinger, R., and Rasmussen, R. A.: Forest thinning experiment confirms ozone deposition to forest canopy is dominated by reaction with biogenic VOCs, Geophys. Res. Lett., 31, L22106, doi: 10.1029/2004GL21259, 2004.

Goldstein, A. H. and Galbally, I. E.: Known and unexplored organic constituents in the earth's atmosphere, Environ. Sci. Technol., 41, 1514-1521, 2007.

Hasson, A. S., Chung, M. Y., Kuwata, K. T., Converse, A. D., Krohn, D., and Paulson, S. E.: Reaction of Criegee intermediates with water vapor - An additional source of $\mathrm{OH}$ radicals in alkene ozonolysis?, J. Phys. Chem. A., 107, 6176-6182, 2003.

Hasson, A. S., Tyndall, G. S., and Orlando, J. J.: A product yield study of the reaction of $\mathrm{HO} 2$ radicals with ethyl peroxy (C2H5O2), acetyl peroxy $(\mathrm{CH} 3 \mathrm{C}(\mathrm{O}) \mathrm{O}-2)$, and acetonyl peroxy (CH3C $(\mathrm{O}) \mathrm{CH} 2 \mathrm{O} 2)$ radicals, J. Phys. Chem. A., 108, 5979-5989, 2004.

Heard, D. E. and Pilling, M. J.: Measurement of $\mathrm{OH}$ and $\mathrm{HO}_{2}$ in the troposphere, Chem. Rev., 103, 5163-5198, 2003.

Hofzumahaus, A., Aschmutat, U., Hessling, M., Holland, F., and Ehhalt, D. H.: The measurement of tropospheric $\mathrm{OH}$ radicals by laser-induced fluorescence spectroscopy during the POPCORN field campaign, Geophys. Res. Lett., 23, 2541-2544, 1996.

Holland, F., Hofzumahaus, A., Schafer, R., Kraus, A., and Patz, $\mathrm{H}$. W.: Measurements of $\mathrm{OH}$ and $\mathrm{HO}_{2}$ radical concentrations and photolysis frequencies during BERLIOZ, J. Geophys. Res.Atmos., 108, 8246, doi:10.1029/2001JD001393, 2003.

Holzinger, R., Lee, A., Paw, K. T., and Goldstein, A. H.: Observations of oxidation products above a forest imply biogenic emissions of very reactive compounds, Atmos. Chem. Phys., 5, 6775, 2005, http://www.atmos-chem-phys.net/5/67/2005/.

Jeanneret, F., Kirchner, F., Clappier, A., van den Bergh, H., and Calpini, B.: Total VOC reactivity in the planetary boundary layer 1. Estimation by a pump and probe $\mathrm{OH}$ experiment, J. Geophys. Res.-Atmos., 106, 3083-3093, 2001. 
Karl, T., Potosnak, M., Guenther, A., Clark, D., Walker, J., Herrick, J. D., and Geron, C.: Exchange processes of volatile organic compounds above a tropical rain forest: Implications for modeling tropospheric chemistry above dense vegetation, J. Geophys. Res.-Atmos., 109, D18306, doi:10.1029/2004JD004738, 2004.

Kovacs, T. A. and Brune, W. H.: Total $\mathrm{OH}$ loss rate measurement, J. Atmos. Chem., 39, 105-122, 2001.

Kovacs, T. A., Brune, W. H., Harder, H., Martinez, M., Simpas, J. B., Frost, G. J., Williams, E., Jobson, T., Stroud, C., Young, V., Fried, A., and Wert, B.: Direct measurements of urban $\mathrm{OH}$ reactivity during Nashville SOS in summer 1999, J. Environ. Monit., 5, 68-74, 2003.

Lelieveld, J., Dentener, F. J., Peters, W., and Krol, M. C.: On the role of hydroxyl radicals in the self-cleansing capacity of the troposphere, Atmos. Chem. Phys., 4, 2337-2344, 2004,

http://www.atmos-chem-phys.net/4/2337/2004/.

Lewis, A. C., Carslaw, N., Marriott, P. J., Kinghorn, R. M., Morrison, P., Lee, A. L., Bartle, K. D., and Pilling, M. J.: A larger pool of ozone-forming carbon compounds in urban atmospheres, Nature, 405, 778-781, 2000.

Lindinger, W., Hansel, A., and Jordan, A.: On-line monitoring of volatile organic compounds at pptv levels by means of protontransfer-reaction mass spectrometry (PTR-MS) - Medical applications, food control and environmental research, Int. J. Mass Spectrom., 173, 191-241, 1998a.

Lindinger, W., Hansel, A., and Jordan, A.: Proton-transfer-reaction mass spectrometry (PTR-MS): on-line monitoring of volatile organic compounds at pptv levels, Chem. Soc. Rev., 27, 347-354, 1998b.

Maris, C., Chung, M. Y., Lueb, R., Krischke, U., Meller, R., Fox, M. J., and Paulson, S. E.: Development of instrumentation for simultaneous analysis of total non-methane organic carbon and volatile organic compounds in ambient air, Atmos. Environ., 37, S149-S158, 2003.

Martinez, M., Harder, H., Kovacs, T. A., et al.: $\mathrm{OH}$ and $\mathrm{HO}_{2}$ concentrations, sources, and loss rates during the Southern Oxidants Study in Nashville, Tennessee, summer 1999, J. Geophys. Res.Atmos., 108(D19), 4617, doi:10.1029/2003JD003551, 2003.

Olson, J. R., Crawford, J. H., Chen, G., et al.: Testing fast photochemical theory during TRACE-P based on measurements of $\mathrm{OH}, \mathrm{HO}_{2}$, and $\mathrm{CH}_{2} \mathrm{O}$, J. Geophys. Res.-Atmos., 109, D15S10, doi:10.1029/2003JD004278, 2004.

Paulson, S. E., Chung, M. Y., and Hasson, A. S.: OH radical formation from the gas-phase reaction of ozone with terminal alkenes and the relationship between structure and mechanism, J. Phys. Chem. A., 103, 8125-8138, 1999.

Poppe, D., Zimmermann, J., Bauer, R., et al.: Comparison Of Measured Oh Concentrations With Model-Calculations, J. Geophys. Res.-Atmos., 99, 16633-16 642, 1994.

Ren, X. R., Brune, W. H., Cantrell, C. A., Edwards, G. D., Shirley, T., Metcalf, A. R., and Lesher, R. L.: Hydroxyl and peroxy radical chemistry in a rural area of Central Pennsylvania: Observations and model comparisons, J. Atmos. Chem., 52, 231-257, 2005.

Ren, X. R., Brune, W. H., Oliger, A., Metcalf, A. R., Simpas, J. B., Shirley, T., Schwab, J. J., Bai, C. H., Roychowdhury, U., Li, Y. Q., Cai, C. X., Demerjian, K. L., He, Y., Zhou, X. L., Gao, H. L., and Hou, J.: $\mathrm{OH}, \mathrm{HO}_{2}$, and $\mathrm{OH}$ reactivity during the PMTACS-NY Whiteface Mountain 2002 campaign: Obser- vations and model comparison, J. Geophys. Res.-Atmos., 111, D10S03, doi:10.1029/2005JD006126, 2006.

Ren, X. R., Harder, H., Martinez, M., Lesher, R. L., Oliger, A., Shirley, T., Adams, J., Simpas, J. B., and Brune, W. H.: $\mathrm{HO}_{x}$ concentrations and $\mathrm{OH}$ reactivity observations in New York City during PMTACS-NY2001, Atmos. Environ., 37, 3627-3637, 2003.

Roberts, J. M., Bertman, S. B., Jobson, T., Niki, H., and Tanner, R.: Measurement of total nonmethane organic carbon (C-y): Development and application at Chebogue Point, Nova Scotia, during the 1993 North Atlantic Regional Experiment campaign, J. Geophys. Res.-Atmos., 103, 13 581-13 592, 1998.

Sadanaga, Y., Yoshino, A., Kato, S., and Kajii, Y.: Measurements of $\mathrm{OH}$ reactivity and photochemical ozone production in the urban atmosphere, Environ. Sci. Technol., 39, 8847-8852, 2005.

Sadanaga, Y., Yoshino, A., Kato, S., Yoshioka, A., Watanabe, K., Miyakawa, Y., Hayashi, I., Ichikawa, M., Matsumoto, J., Nishiyama, A., Akiyama, N., Kanaya, Y., and Kajii, Y.: The importance of NO2 and volatile organic compounds in the urban air from the viewpoint of the $\mathrm{OH}$ reactivity, Geophys. Res. Lett., 31, L08102, doi:10.1029/2004GL0196612004a.

Sadanaga, Y., Yoshino, A., Watanabe, K., Yoshioka, A., Wakazono, Y., Kanaya, Y., and Kajii, Y.: Development of a measurement system of $\mathrm{OH}$ reactivity in the atmosphere by using a laser-induced pump and probe technique: Rev. Sci. Instrum., 75, 2648-2655, 2004b.

Salisbury, G., Williams, J., Holzinger, R., Gros, V., Mihalopoulos, N., Vrekoussis, M., Sarda-Esteve, R., Berresheim, H., von Kuhlmann, R., Lawrence, M., and Lelieveld, J.: Ground-based PTR-MS measurements of reactive organic compounds during the MINOS campaign in Crete, July-August 2001, Atmos. Chem. Phys., 3, 925-940, 2003, http://www.atmos-chem-phys.net/3/925/2003/.

Shirley, T. R., Brune, W. H., Ren, X., Mao, J., Lesher, R., Cardenas, B., Volkamer, R., Molina, L. T., Molina, M. J., Lamb, B., Velasco, E., Jobson, T., and Alexander, M.: Atmospheric oxidation in the Mexico City Metropolitan Area (MCMA) during April 2003, Atmos. Chem. Phys., 6, 2753-2765, 2006, http://www.atmos-chem-phys.net/6/2753/2006/.

Sickles, J. E., Eaton, W. C., Ripperton, L. A., and Wright, R. S.: US Environmental Protection Agency, EPA-60017-77-104, 1977.

Sinha, V., Williams, J., Meyerhofer, M., Riebesell, U., Paulino, A. I., and Larsen, A.: Air-sea fluxes of methanol, acetone, acetaldehyde, isoprene and DMS from a Norwegian fjord following a phytoplankton bloom in a mesocosm experiment, Atmos. Chem. Phys., 7, 739-755, 2007a, http://www.atmos-chem-phys.net/7/739/2007/.

Sinha, V., Williams, J., Crutzen P., and Lelieveld J.: Methane emissions from boreal and tropical forest ecosystems derived from in-situ measurements, Atmos. Chem. Phys. Discuss., 7, 14011$14039,2007 b$.

Smith, S. C., Lee, J. D., Bloss, W. J., Johnson, G. P., Ingham, T., and Heard, D. E.: Concentrations of $\mathrm{OH}$ and $\mathrm{HO} 2$ radicals during NAMBLEX: measurements and steady state analysis, Atmos. Chem. Phys., 6, 1435-1453, 2006, http://www.atmos-chem-phys.net/6/1435/2006/.

Williams, J., Poschl, U., Crutzen, P. J., Hansel, A., Holzinger, R., Warneke, C., Lindinger, W., and Lelieveld, J.: An atmospheric chemistry interpretation of mass scans obtained from a proton 
transfer mass spectrometer flown over the tropical rainforest of Surinam, J. Atmos. Chem., 38, 133-166, 2001.

Williams, J., Yassaa, N., Bartenbach, S., and Lelieveld, J.: Mirror image hydrocarbons from Tropical and Boreal forests, Atmos. Chem. Phys., 7, 973-980, 2007,

http://www.atmos-chem-phys.net/7/973/2007/.
Yoshino, A., Sadanaga, Y., Watanabe, K., Kato, S., Miyakawa, Y., Matsumoto, J., and Kajii, Y.: Measurement of total OH reactivity by laser-induced pump and probe technique - comprehensive observations in the urban atmosphere of Tokyo, Atmos. Environ., 40, 7869-7881, 2006. 